\title{
Modulatory Effects of Bacillus subtilis on the Performance, Morphology, Cecal Microbiota and Gut Barrier Function of Laying Hens
}

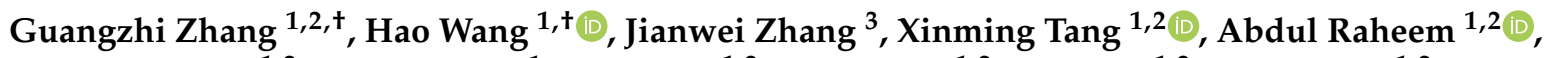 \\ Mingyan Wang ${ }^{1,2}$, Weidong Lin ${ }^{1}$, Lin Liang ${ }^{1,2}$, Yuzhuo Qi ${ }^{1,2}$, Yali Zhu ${ }^{1,2}$, Yaxiong Jia ${ }^{1,2, *}$, Shangjin Cui ${ }^{1,2, *}$ \\ and Tong Qin $1,2, *$
}

1 Institute of Animal Sciences, Chinese Academy of Agricultural Sciences, Beijing 100193, China; zhangguangzhi@caas.cn (G.Z.); wanghao_3001@163.com (H.W.); tangxinming@caas.cn (X.T.); 2019y90100011@caas.cn (A.R.); mingyan.wang@ceva.com (M.W.); linweidong@caas.cn (W.L.); lianglin@caas.cn (L.L.); qyz0314@163.com (Y.Q.); zyl41018@126.com (Y.Z.)

2 Scientific Observation and Experiment Station of Veterinary Drugs and Diagnostic Technology of Beijing, Ministry of Agriculture, Beijing 100193, China

3 Beijing General Station of Animal Husbandry, Beijing 100107, China; zjw7432@126.com

* Correspondence: jiayaxiong@caas.cn (Y.J.); cuishangjin@caas.cn (S.C.); qintong@caas.cn (T.Q.)

+ These authors contributed equally.

check for updates

Citation: Zhang, G.; Wang, H.; Zhang, J.; Tang, X.; Raheem, A.; Wang, M.; Lin, W.; Liang, L.; Qi, Y.; Zhu, Y.; et al. Modulatory Effects of Bacillus subtilis on the Performance, Morphology, Cecal Microbiota and Gut Barrier Function of Laying Hens. Animals 2021, 11, 1523. https:// doi.org/10.3390/ani11061523

Academic Editor: Marco Zampiga

Received: 29 April 2021

Accepted: 18 May 2021

Published: 24 May 2021

Publisher's Note: MDPI stays neutral with regard to jurisdictional claims in published maps and institutional affiliations.

Copyright: (c) 2021 by the authors. Licensee MDPI, Basel, Switzerland. This article is an open access article distributed under the terms and conditions of the Creative Commons Attribution (CC BY) license (https:// creativecommons.org/licenses/by/ $4.0 /)$.
Simple Summary: The excessive or improper use of antibiotics in chicken feed has led to the emergence of antibiotic-resistant bacteria, drug residues in the tissue, and other relevant issues, and this situation is severe in China. From 31 December 2020, antibiotics were banned for use as supplemental growth promoters in animal feed in China; therefore, antibiotic substitutes are urgently needed in China. People are searching for ideal antibiotic alternatives, and probiotics have proven their potential use for this. Our current trial aims to evaluate the effects of the Bacillus subtilis (B. subtilis) YW1 strain on laying hens, including the effects on performance, morphology, cecal microbiota, and intestinal barrier function. Our study showed that orally administering laying hens with probiotic B. subtilis cannot significantly improve their overall egg production, can induce a healthier microbiota composition characterized by a higher ratio of beneficial bacteria, and strengthens the physical barrier function of the intestine by inducing a higher expression of the tight junction protein. This makes it a valid probiotic alternative to antibiotics, and also a reference strain for clinical application in the poultry industry.

Abstract: We investigated the efficacy of a single bacterium strain, Bacillus subtilis (B. subtilis) YW1, on the performance, morphology, cecal microbiota, and intestinal barrier function of laying hens. A total of 216 28-week-old Hy-line Brown laying hens were divided into three dietary treatment groups, with six replicates of 12 birds each for 4 weeks. The control group (Ctr) was fed a basal diet and the treatment groups, T1 and T2, were fed a basal diet supplemented with B. subtilis at a dose rate of $5 \times 10^{8} \mathrm{CFU} / \mathrm{kg}$ and $2.5 \times 10^{9} \mathrm{CFU} / \mathrm{kg}$, respectively. Dietary supplementation with $B$. subtilis did not significantly affect overall egg production in both groups, with no obvious changes in average egg weight and intestine morphology. B. subtilis administration also improved the physical barrier function of the intestine by inducing significantly greater expression levels of the tight junction protein occludin in T1 $(p=0.07)$ and T2 $(p<0.05)$. Further, supplementation with B. subtilis effectively modulated the cecal microbiota, increasing the relative level of beneficial bacteria at the genus level (e.g., Bifidobacterium $p<0.05$, Lactobacillus $p=0.298$, Bacillus $p=0.550$ ) and decreasing the level of potential pathogens (e.g., Fusobacterium $p<0.05$, Staphylococcus $p<0.05$, Campylobacter $p=0.298$ ). Overall, B. subtilis YW1 supplementation cannot significantly improve the egg production; however, it modulated the cecal microbiota towards a healthier pattern and promoted the mRNA expression of the tight junction protein occludin in laying hens, making B. subtilis YW1 a good probiotic candidate for application in the poultry industry, and further expanding the resources of strains of animal probiotics. 
Keywords: Bacillus subtilis; cecal microbiota; barrier function; occludin; probiotic

\section{Introduction}

In order to inhibit the pathogenic bacteria in the gut and improve feed conversion ratio and meat production, chicken feed could be supplemented with a daily low dose of antibiotics, especially in commercial poultry farms worldwide [1,2]. However, increasing evidence indicates that the excessive or indiscriminate use of antibiotics in the feed of chickens and livestock may lead to the emergence of antibiotic-resistant bacteria or drug residues in the tissue, and may also compromise the efficacy of antibiotic treatment [3-5]. Further, this excessive use of antibiotics poses a threat to public health due to the potential transfer of antibiotic resistance genes between animal-derived products and humans. Thus far, antibiotic resistance (ABR) has been a worldwide issue in both farm animals and public health. Supplementing feed with antibiotics as a growth promoter is already prohibited in Europe, the U.S., and some other countries, such as China, which banned antibiotics supplementation in feed in 2020 [6]. Paradoxically, the prohibition of antibiotics in livestock and poultry feed has caused a relative increase in bacterial infection, and reduced the quality and performance of animals and poultry [2,7]. As such, researchers are searching for ideal antibiotic substitutes, and numerous studies have shown that some probiotics and prebiotics possess health-promoting and disease-preventing abilities in both humans and animals.

Probiotics are defined as "live microorganisms which when administered in adequate amounts confer a health benefit on the host" by the World Health Organization [8]. Considerable efforts are being made to find probiotic alternatives to antibiotics and, currently, the majority of probiotics employed in chicken farming are Lactobacillus (L.) spp., Bifidobacterium spp., Bacillus (B.) spp., or Enterococcus spp. [6,9-11]. Tailored probiotics can modulate the microbiome, mycobiome, and host gene expression of turkeys in a manner similar to low doses of antibiotic growth promoter [12]. The administration of L. salivarius or L. plantarum in feed significantly increases the levels of short-chain fatty acids and induces a healthier pattern in the intestinal microbiota of broiler chickens [13,14]. Dietary supplementation with $B$. subtilis has positive effects on productivity, the stimulation of immune activities, and the improvement of antioxidant capacity in broilers [15]. Dietary supplementation with Enterococcus faecalis strain UGRA10 increases the ileum and caecum bacterial diversity in laying hens [16]. Amongst the probiotic species, Bacillus are popular feed additives due to their spore-producing abilities, which can counteract the extreme conditions and stresses the host is subjected to.

We have evaluated the safety and potential effects of B. subtilis on the performance, morphology, gut barrier function, and cecal microbiota of laying hens after administration for 4 weeks.

\section{Materials and Methods}

\subsection{Probiotic Preparation}

The Bacillus subtilis strain YW1 used in this study was isolated, characterized, and stored by our lab; this strain showed a high acid-resistant ability and antimicrobial ability in vitro. B. subtilis was added to basal feed as a freeze-dried powder. The freeze-dried B. subtilis was supplemented homogeneously to the basal diet up to $5 \times 10^{8} \mathrm{CFU} / \mathrm{kg}$ and $2.5 \times 10^{9} \mathrm{CFU} / \mathrm{kg}$.

\subsection{Laying Hens and Farm Facilities}

The experimental group consisted of 216 28-week-old Hy-line Brown laying hens, and was divided into 3 groups, each containing 6 replicates with 12 birds in 1 replicate. The control group (Ctr) received only the basal diet, treatment group 1 (T1) received the basal diet supplemented with B. subtilis at a dosage of $5 \times 10^{8} \mathrm{CFU} / \mathrm{kg}$, and treatment group 2 
(T2) received the basal diet supplemented with B. subtilis at a dosage of $2.5 \times 10^{9} \mathrm{CFU} / \mathrm{kg}$ for 4 weeks. In this experiment, the chickens were fed a corn-soybean basal diet, which was antibiotic-free and formulated to meet the nutrient requirements of laying hens.

The ingredients of the basal diet used in this study are shown in Table 1.

Cage distribution was equal between the upper and lower cage levels to minimize any effect of the cage level. All the chickens were housed in steel wire cages $(57 \times 47 \times 47 \mathrm{~cm})$ with 3 birds per cage. The ambient temperature and room humidity of the farm facility were maintained at $19 \pm 2{ }^{\circ} \mathrm{C}$ and $45 \sim 65 \%$, respectively. The photoperiod was set to $16: 8$ light:dark throughout the study.

Table 1. Composition of the experimental diets for laying hens (as-fed basis, \%, unless otherwise indicated).

\begin{tabular}{cccc}
\hline Ingredients & \multicolumn{2}{c}{ Nutrient Level $^{\mathbf{2}}$} \\
\hline Corn (\%) & 62.85 & $\mathrm{CP}(\%)$ & 16.51 \\
Soybean meal (\%) & 26.35 & $\mathrm{ME} \mathrm{(MJ/kg)}$ & 11.16 \\
Limestone (\%) & 9.00 & Calcium (\%) & 3.4 \\
CaHPO $_{4}(\%)$ & 1.00 & $\mathrm{AP}(\%)$ & 0.34 \\
Premix $^{1}(\%)$ & 0.65 & $\mathrm{TP} \%)$ & 0.66 \\
DL-Met $(\%)_{\text {Total }}$ & 0.15 & Met & 0.42 \\
& 100.00 & Lys & 0.86 \\
& & Met + Cys & 0.72 \\
& & Lys/Met & 2.06 \\
\hline
\end{tabular}

${ }^{1}$ The premix provided the following per kg to the diet: VA $12,500 \mathrm{IU}, \mathrm{VD}_{3} 4125 \mathrm{IU}, \mathrm{VE} 15 \mathrm{IU}, \mathrm{VK} 2 \mathrm{mg}$, thiamine $1 \mathrm{mg}$, riboflavin $8.5 \mathrm{mg}$, calcium pantothenate $50 \mathrm{mg}$, nicotinic acid $32.5 \mathrm{mg}$, pyridoxine $8 \mathrm{mg}, \mathrm{VB}_{12} 5 \mathrm{mg}$, biotin $2 \mathrm{mg}$, Fe (as ferrous sulfate) $60 \mathrm{mg}$, Cu (as copper sulfate) $8 \mathrm{mg}$, Zn (as zinc sulfate) $66 \mathrm{mg}$, Mn $65 \mathrm{mg}$, Se $0.3 \mathrm{mg}$, I $1 \mathrm{mg}$, choline $0.5 \mathrm{~g}$, phytase $0.5 \mathrm{~g}, \mathrm{NaCl} 3.0 \mathrm{~g}$. ${ }^{2}$ The data on nutrients depict the measured content except ME and non-phytate phosphorus.

\section{Experimental Procedure}

\subsection{Ethics Statement}

This bird trial was evaluated and approved by the local ethic committee of the Institute of Animal Science, Chinese Academy of Agricultural Science (IAS2019-71), China. The experimental protocol was carried out in strict accordance with the relevant guidelines.

\subsection{Hens Performance}

Eggs from each replicate were collected and counted once a day. Egg weight was monitored daily and was calculated as the mean weight of all eggs from each replicate.

\subsection{Intestinal Morphology}

At the end of the trial, one bird from each replicate was randomly selected for euthanasia. Approximately $5 \mathrm{~cm}$ of the jejunum was cut from the midpoint between the point of bile duct entry and Meckel's diverticulum. The tissue was gently flushed several times with physiological saline $(1 \% \mathrm{NaCl})$ to remove intestinal contents, and then placed in $10 \%$ formalin for fixation. The intestinal samples were dehydrated and embedded in paraffin following routine procedures. A $3 \mu \mathrm{m}$ thick tissue section was taken and stained with hematoxylin and eosin for histological observation. The intestinal morphology was evaluated via light microscopy (Olympus, Tokyo, Japan).

The villus' height and crypt depth were measured in around five to seven randomly selected villi and associated crypts per hen, at $10 \times$ combined magnification, and the villus height/crypt depth ratio (VCR) was also calculated.

\subsection{Quantitative Real-Time PCR}

To determine the immune-related gene transcript levels in the jejunum, total RNA was extracted from the jejunal tissue with Trizol reagent (Ambion, Carishad, CA, USA), according to the manufacturer's protocol as described elsewhere [17]. In brief, jejunal 
tissue ( $100 \mathrm{mg}$ ) was collected and kept in $1 \mathrm{~mL}$ of RNAlater solution (Invitrogen, Vilnius, Lithuana) at $-70^{\circ} \mathrm{C}$ until further RNA extraction. The tissue was first homogenized with IKA T10 basic ULTRA-TURRAX (IKA, Königswinter, Germany), and then resuspended with Trizol reagent, followed by phase separation via chloroform and RNA precipitation and, finally, clean-up. The RNA concentration and purity were measured using NanoVue Plus (Biochrom, Cambridge, UK).

The RNA concentration of all samples was adjusted to $0.5 \mu \mathrm{g} / \mu \mathrm{L}$, and cDNA was synthesized immediately from $2 \mu \mathrm{g}$ of purified RNA using the FastKing RT Kit with gDNase (Tiangen Biotech Co., Ltd., Beijing, China).

The housekeeping genes $\beta$-Actin and GAPDH were used as reference genes. The mRNA expression levels of the target genes (Occludin, TLR1, TLR2, TLR4, TLR15, TNFSF15, LYZ) were quantified using SYBR Green-based RT-PCR with ChamQ Universal SYBR qPCR Master Mix (Vazyme Biotech Co., Ltd., Nanjing, China). The primers were synthesized with BGI (Beijing, China), and are shown in Table 2. The reactions were performed using a CFX96 RT-PCR System in a C1000 Thermal Cycler (Bio-Rad). All reactions were performed in $20 \mu \mathrm{L}$ volumes containing $0.5 \mu \mathrm{L}$ of each primer $(1.25 \mathrm{pmol} / \mu \mathrm{L}), 10 \mu \mathrm{L}$ ChamQ Universal SYBR qPCR Master Mix, $7 \mu \mathrm{L}$ HPLC water, and $2 \mu \mathrm{L}$ cDNA. The experimental program was as follows: $95^{\circ} \mathrm{C}$ for $30 \mathrm{~s}$, followed by 40 cycles of denaturation at $95^{\circ} \mathrm{C}$ for $10 \mathrm{~s}$, annealing at $60{ }^{\circ} \mathrm{C}$ for $30 \mathrm{~s}$, and extension at $72{ }^{\circ} \mathrm{C}$ for $30 \mathrm{~s}$. The melting curves were analyzed for the specific amplifications of all genes. The threshold cycle values $(\mathrm{Ct})$ were normalized to the geometric means of the reference genes, and the normalized mRNA levels of all target genes were calculated using the $2^{-\Delta \Delta \mathrm{Ct}}$ method [18].

Table 2. Sequence information of primers used for real-time PCR.

\begin{tabular}{|c|c|c|c|c|}
\hline Genes & GenBank Number & Forward Sequence $\left(5^{\prime}\right.$ to $\left.3^{\prime}\right)$ & Reverse Sequence $\left(5^{\prime}\right.$ to $\left.3^{\prime}\right)$ & Reference \\
\hline$\beta$-Actin & NM_205518.1 & ACTCTGGTGATGGTGTTAC & GGCTGTGATCTCCTTCTG & [19] \\
\hline GAPDH & AF047874 & GAAGGCTGGGGCTCATCTG & CAGTTGGTGGTGCACGATG & [20] \\
\hline Occludin & NM_205128.1 & TCATCGCCTCCATCGTCTAC & TCTTACTGCGCGTCTTCTGG & [19] \\
\hline TLR1 & AB109401.1 & GGCAGTGGACGCAGACAAA & GTAGGAAATGAAGGCGTGGAA & [21] \\
\hline TLR2 & NM_204.278 & CTGGGAAGTGGATTGTGGA & AAGGCGAAAGTGCGAGAAA & [22] \\
\hline TLR4 & NM_001030693.1 & TTCCAAGCACCAGATAGCAACATC & ACGGGTCACAGAAGAACTTAGGG & [23] \\
\hline TLR15 & JN112029.1 & ATCCTTGTCGTTCTGGTGCTAA & TCAGTAGATGCTCCTTCGTCCA & [21] \\
\hline TNFSF15 & NM010245578 & CCTGAGTATTCCAGCAACGCA & ATCCACCAGCTTGATGTCACTAAC & [22] \\
\hline LYZ & NM 205.281 & CTGGGAAACTGGGTGTGTGT & AGCGGCTGTTGATCTGTAGG & [22] \\
\hline
\end{tabular}

\subsection{Cecal Microbiota Analysis by $16 S$ rRNA High-Throughput Sequencing}

The cecal content was collected, snap-frozen, and kept at $-70{ }^{\circ} \mathrm{C}$ until further DNA extraction. DNA was extracted using the E.Z.N.A. ${ }^{\circledR}$ Stool DNA Kit (D4015, Omega, Inc., Norcross, GA, USA), according to the manufacturer's instructions. A reagent designed to extract DNA from trace amounts of sample has been shown to be effective for the preparation of DNA from most bacteria. Nuclease-free water was used for the blank. The total DNA was eluted in $50 \mu \mathrm{L}$ of elution buffer and stored at $-80{ }^{\circ} \mathrm{C}$ until measurement in the PCR at LC-Bio Technology Co., Ltd., Hang Zhou, Zhejiang province, China.

The V3-V4 region of $16 \mathrm{~S}$ rRNA gene was amplified with primers $341 \mathrm{~F}\left(-5^{\prime} \mathrm{CCTACGGG}\right.$ NGGCWGCAG3' and 805R -5'GACTACHVGGGTATCTAATCC3'. The 5' ends of the primers were tagged with specific barcodes per sample and sequencing universal primers. PCR amplification was performed in a $25 \mu \mathrm{L}$ total volume of reaction mixture containing $25 \mathrm{ng}$ of template DNA, $12.5 \mu \mathrm{L}$ PCR premix, $2.5 \mu \mathrm{L}$ of each primer, and PCR-grade water to adjust the volume. The PCR program for amplifying the prokaryotic $16 \mathrm{~S}$ fragments was as follows: initial denaturation at $98{ }^{\circ} \mathrm{C}$ for $30 \mathrm{~s} ; 32$ cycles of denaturation at $98{ }^{\circ} \mathrm{C}$ for $10 \mathrm{~s}$, annealing at $54{ }^{\circ} \mathrm{C}$ for $30 \mathrm{~s}$, and extension at $72{ }^{\circ} \mathrm{C}$ for $45 \mathrm{~s}$; and then final extension at $72{ }^{\circ} \mathrm{C}$ for $10 \mathrm{~min}$. The PCR samples were checked with $2 \%$ agarose gel electrophoresis. Throughout the DNA extraction process, ultrapure water (instead of sample solution) was used as a negative control to prevent false-positive PCR results. The PCR samples 
were purified with AMPure XT beads (Beckman Coulter Genomics, Danvers, MA, USA) and quantified via Qubit (Invitrogen, Waltham, MA, USA). The amplicon pools were prepared for further sequencing. The sizes and quantities within the amplicon library were assessed using an Agilent 2100 Bioanalyzer (Agilent, Santa Clara, CA, USA) and the Library Quantification Kit for Illumina (Kapa Biosciences, Woburn, MA, USA), respectively. The libraries were sequenced on the Nova Seq PE250 platform.

\subsection{Sequencing Data Analysis}

The samples were sequenced on an Illumina NovaSeq platform from LC-Bio, based on the manufacturer's recommendations. Paired-end reads were assigned to samples based on their unique barcode, and then truncated by cutting off the barcode and primer sequence. The paired-end reads were merged using FLASH. The raw tags were quality-filtered under specific filtering conditions to obtain high-quality clean tags according to the fqtrim (V 0.94). Chimeric sequences were filtered using Vsearch software (v2.3.4). Sequences with $\geq 97 \%$ similarity were assigned to the same operational taxonomic unit (OTU) by Vsearch (v2.3.4). Representative sequences were chosen for each OTU, and taxonomic data were then assigned to each representative sequence using the RDP (ribosomal database project) classifier. The OTU abundance information was normalized using a standard sequence number corresponding to the sample with the least sequences. Alpha diversity was used to analyze the species diversity of a sample via several indicators, such as Chao1, Shannon, Simpson, etc., all of which were calculated with QIIME (Version 1.8.0). Beta diversity analyses were used to assess differences in complexity between species, and were calculated via PCoA and cluster analysis with QIIME software. Blast was used for sequence alignment, and the OTU representative sequences were annotated with the RDP (ribosome database) and NCBI-16S database for individual representative sequences.

\subsection{Statistical Analysis}

The differences in performance and the mRNA expression levels of different genes in laying hens were assessed with one-way ANOVA, followed by a Bonferroni post hoc test. Differences in the composition and relative abundance of microbiota were assessed with the Wilcoxon rank-sum test. Each replicate served as the experimental unit for the parameters examined, and $p$ values less than 0.05 were considered statistically significant. All data are expressed as mean \pm SD. The clean data were analyzed and presented using Majorbio Cloud (Majorbio Bio-Pharm Technology Co., Ltd., Shanghai, China). The rest of the figures were created using GraphPad Prism5 software (GraphPad Software Inc., San Diego, CA, USA).

\section{Results}

4.1. Effects of B. subtilis Supplementation on Overall Performance and Morphology of the Jejunum of Laying Hens

No birds died or showed any signs of clinical disease throughout the experimental trial. Prior to B. subtilis supplementation, baseline egg production and egg weight were monitored for 1 week. No significant difference was observed between control group and T1, T2 groups in terms of egg production (Table 3) and egg weight (Table 3). As shown in Table 3, compared to the control group fed a normal diet, egg production in T1 and T2 (fed diets with $B$. subtilis supplementation) did not show a significant increase over the whole experimental period. Average egg weight showed no significant differences between any groups (Table $3, p>0.05$ ). 
Table 3. Effects of probiotics on average egg production and weight over the whole experimental period (1 4 week).

\begin{tabular}{cccc}
\hline Parameters & Ctr & T1 & T2 \\
\hline $\begin{array}{c}\text { Egg production }(\%), \\
\text { before treatment } \\
\text { Egg production }(\%), \\
\quad \text { after treatment }\end{array}$ & $92.64 \pm 1.64$ & $92.56 \pm 3.35$ & $93.60 \pm 2.63$ \\
$\begin{array}{c}\text { Egg weight (g), before } \\
\text { treatment }\end{array}$ & $63.11 \pm 1.44$ & $95.99 \pm 1.28$ & $95.19 \pm 1.58$ \\
$\begin{array}{c}\text { Egg weight (g), after } \\
\text { treatment }\end{array}$ & $64.63 \pm 0.960 .72$ & $62.71 \pm 0.76$ & $62.66 \pm 1.03$ \\
\end{tabular}

Ctr: control group fed a basal diet; T1, T2: treatment groups fed a basal diet supplemented with B. subtilis at different doses $\left(\mathrm{T} 1=5 \times 10^{8} \mathrm{CFU} / \mathrm{kg} ; \mathrm{T} 2=2.5 \times 10^{9} \mathrm{CFU} / \mathrm{kg}\right)$. Data are shown as mean $\pm \mathrm{SD}$.

Similarly, compared to the control group, no statistically significant differences in villus height $(p>0.05)$, crypt depth $(p>0.05)$ or villus height/crypt depth ratio $(p>0.05)$ were observed in either treatment group $(\mathrm{T} 1, \mathrm{~T} 2)$ (Table 4$)$.

Table 4. Effects of B. subtilis supplementation on the morphology of the jejunum in laying hens at day 28 of the experiment.

\begin{tabular}{cccc}
\hline Parameters & Ctr & T1 & T2 \\
\hline Villus height $(\mu \mathrm{m})$ & $876.96 \pm 232.38$ & $869.42 \pm 183.76$ & $898 \pm 248.37$ \\
Crypt depth $(\mu \mathrm{m})$ & $76.71 \pm 26.73$ & $76.02 \pm 22.21$ & $75.45 \pm 21.05$ \\
$\begin{array}{c}\text { Villus height/crypt } \\
\text { depth ratio }\end{array}$ & $11.43 \pm 1.15$ & $11.43 \pm 3.91$ & $11.93 \pm 1.51$
\end{tabular}

Ctr: control group fed a basal diet; T1: group fed a basal diet supplemented with B. subtilis $\left(5 \times 10^{8} \mathrm{CFU} / \mathrm{kg}\right)$; T2: group fed by basal diet supplemented with B. subtilis $\left(2.5 \times 10^{9} \mathrm{CFU} / \mathrm{kg}\right)$. Data are shown as mean $\pm \mathrm{SD}$.

\subsection{Effects of B. subtilis Supplementation on Gut Microbiota of Laying Hens}

As shown in Figure 1A, T1 exhibited the greatest number of OUTs, and three groups shared 938 of the OUTs of cecal microbiota. The species richness parameters (Alpha diversity) exhibited no significant differences. PCoA analysis (Beta diversity) revealed a significant distinction between $\mathrm{Ctr}, \mathrm{T} 1$ and $\mathrm{T} 2$ based on unweighted UniFrac distances (Figure 1B). Additionally, ANOSIM analysis, based on unweighted UniFrac distances, showed that the variation between groups was higher than the variation between samples within a single group $(R=0.370, p=0.001$, Figure $1 C)$. The analysis of dominant microbiota at the phylum level showed a similar pattern among the three groups (Figure 1D).

As for the difference in microbiota composition, no significant alterations were observed in the top five most dominant phyla in chickens fed with different diets (Figure 2A). Further analysis of microbiota composition at the genus level showed significant variations in one group of genera (Figure 2A). Compared to Ctr, the relative abundances of 19 and 29 genera were significantly changed in $\mathrm{T} 1$ and $\mathrm{T} 2$, respectively (parts of the data are shown in Figure 2B,C). Compared to Ctr, the relative abundance of Staphylococcus $(p<0.05)$ was reduced (Figure 2B). Moreover, the relative abundances of specific potential pathogens in T2 were reduced or showed a reducing trend, e.g., Fusobacterium $(p<0.05)$, Staphylococcus $(p<0.05)$, Campylobacter $(p=0.298)$. Conversely, the relative abundances of certain beneficial bacteria in the T2 group increased or showed an increasing trend, e.g., Bifidobacterium $(p<0.05)$, Lactobacillus $(p=0.298)$, Bacillus $(p=0.550)$ (Figure 2C). However, the changes in relative abundance were not obvious (Figure 2B). Moreover, compared to $\mathrm{Ctr}$, the relative abundances of other potential pathogens were also significantly reduced, e.g., Enterobacter, Vibrio (data not shown). 


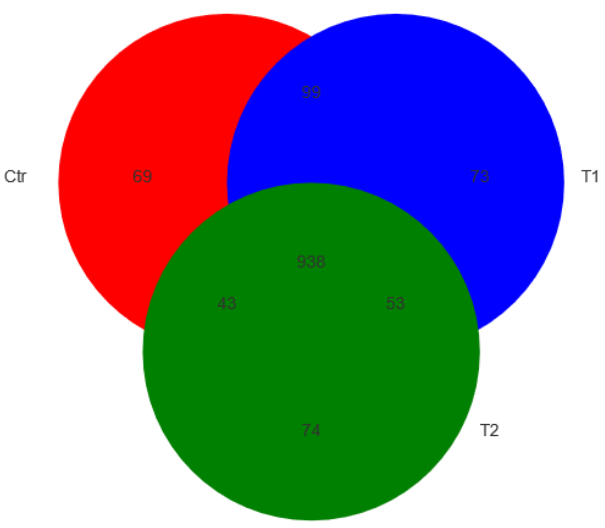

C

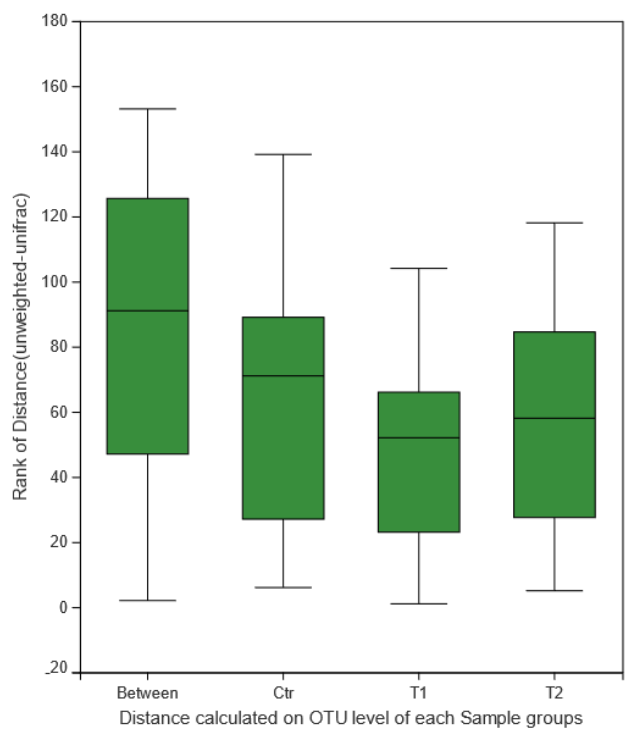

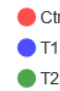

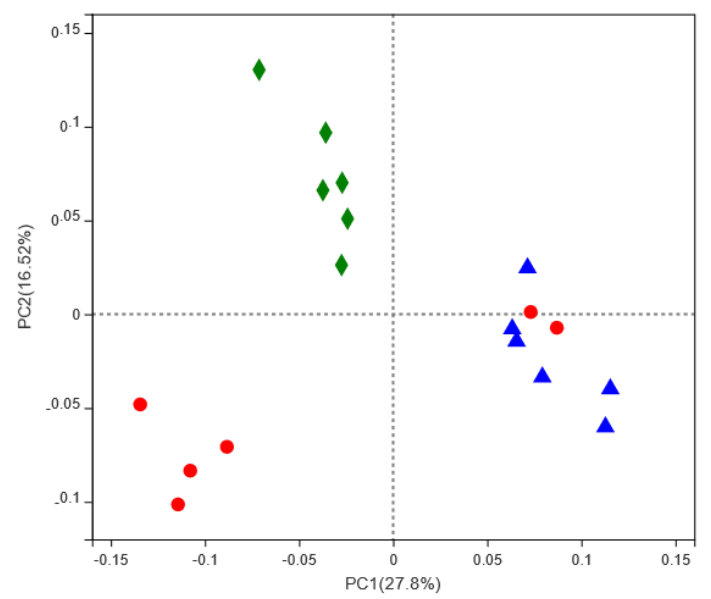

${ }_{\text {T2 }}^{\mathrm{Ctt}}$

D

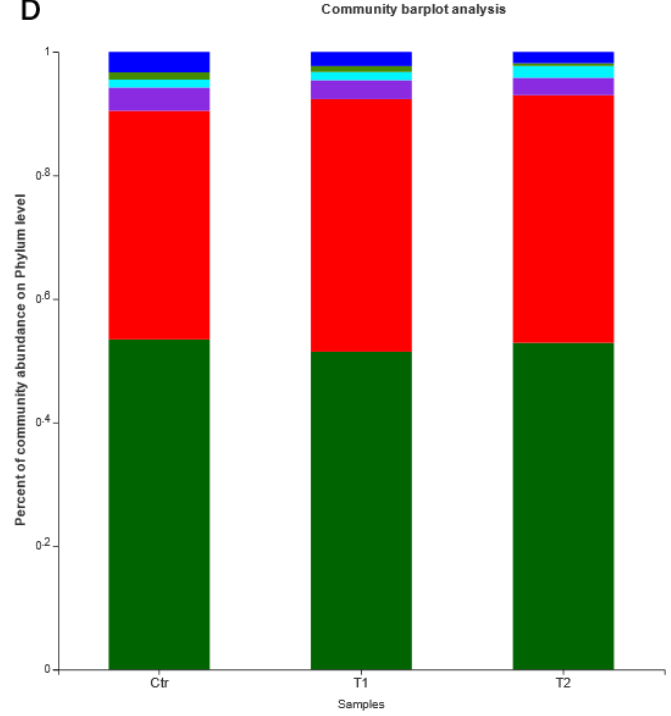

Figure 1. Effects of B. subtilis supplementation on the composition and abundance of cecal microbiota: (A) Venn diagram of OTUs in three groups. (B) Principal coordinate analysis (PCoA) of bacterial beta diversity based on the unweighted UniFrac distances in the three groups. The percentage of variation given by the plotted principal components is marked on both axes. Each spot represents one sample. (C) ANOSIM analysis based on unweighted UniFrac distances. (D) Composition of most dominant microbiota at the phylum level. Ctr: control group fed a basal diet $(n=6)$; T1: group fed a basal diet supplemented with B. subtilis $\left(5 \times 10^{8} \mathrm{CFU} / \mathrm{kg}\right)(n=6)$; T2: group fed a basal diet supplemented with B. subtilis $\left(2.5 \times 10^{9} \mathrm{CFU} / \mathrm{kg}\right)(n=6)$. 


\section{A}

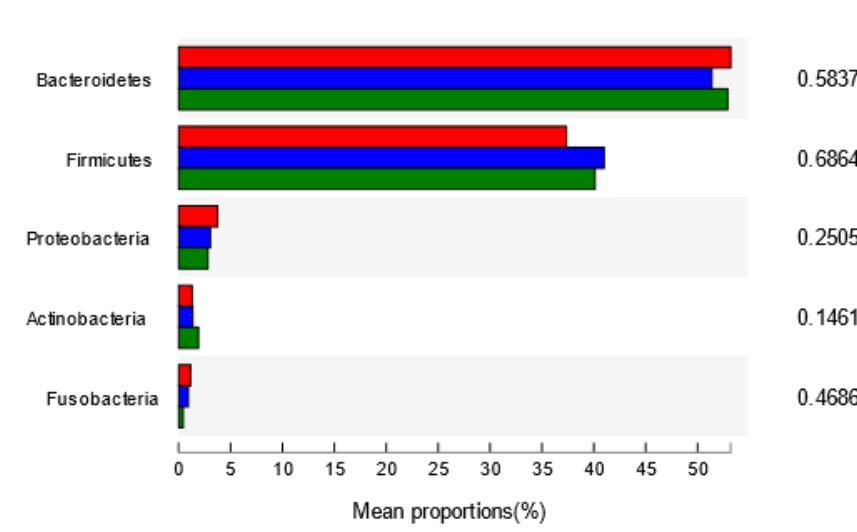

B

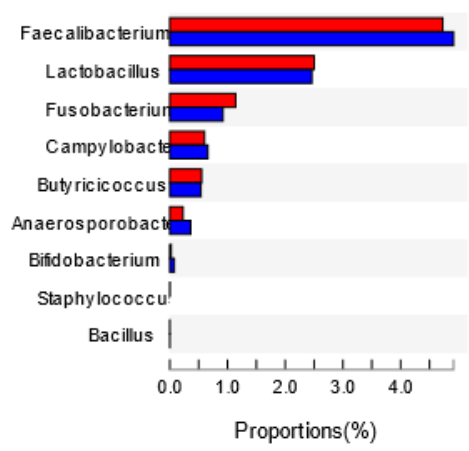

C

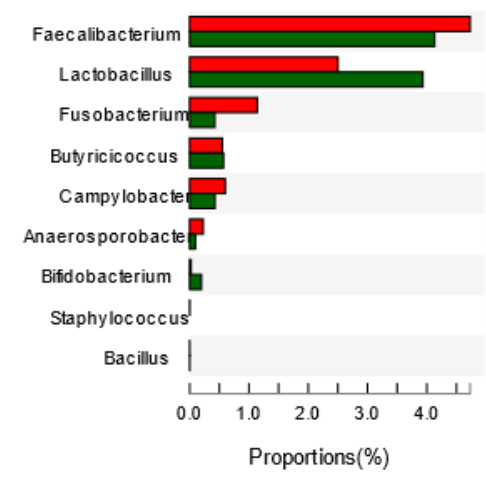

$$
\mathrm{Ct}_{\mathrm{T} 1}^{\mathrm{Ct}}
$$

0.6889

0.9362

0.6889

1

1 ए

0.3776

0.02844

0.775

$\square \mathrm{Ctr}$

T2

Figure 2. Effects of B. subtilis supplementation on the relative abundances of microbiota at the phylum and genus levels: (A) Top 5 most dominant phyla in chickens fed different diets. (B) Relative abundances of representative microbiota at the genus level between the control group and T1. (C) Relative abundances of representative microbiota at the genus level between the control group and T2. Statistical analysis was performed by the Wilcoxon rank-sum test. * indicates a statistically significant difference $(p<0.05)$ between the control group and the probiotic-treated groups (T1, T2). T1: group fed a basal diet supplemented with B. subtilis $\left(5 \times 10^{8} \mathrm{CFU} / \mathrm{kg}\right)$; T2: group fed a basal diet supplemented with B. subtilis $\left(2.5 \times 10^{9} \mathrm{CFU} / \mathrm{kg}\right)$.

\subsection{Changes in Gene mRNA Expression Level in Response to B. subtilis Administration}

As regards the tight junction protein occludin, T2, fed a diet supplemented with B. subtilis $\left(2.5 \times 10^{9} \mathrm{CFU} / \mathrm{kg}\right)$, displayed a statistically significant upregulation compared to chickens fed a basal diet (Figure 3). A similar expression trend was observed in T1; however, there was no statistically significant difference $(p=0.07)$. No significant changes in TLR1, TLR2, TLR4, TLR15, TNFSF15, or LYZ mRNA expression levels were observed between groups (Figure 3). 


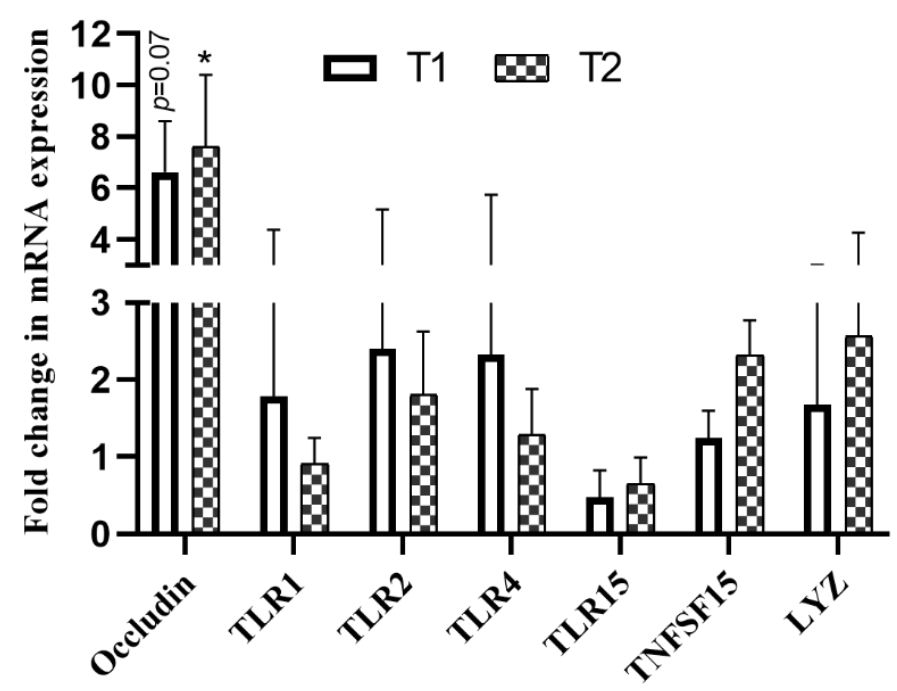

Figure 3. Effects of Bacillus subtilis on mRNA expression of tight junction protein and other immunerelated genes. Mean changes in mRNA expression of several genes in chickens fed a basal diet or a diet supplemented with different doses of B. subtilis. The mean fold change in the control group is equal to $1 .{ }^{*}$ indicates a statistically significant difference $(p<0.05)$ between the control and probiotic-treated groups. T1: group fed a basal diet supplemented with B. subtilis $\left(5 \times 10^{8} \mathrm{CFU} / \mathrm{kg}\right)$; T2: group fed a basal diet supplemented with B. subtilis $\left(2.5 \times 10^{9} \mathrm{CFU} / \mathrm{kg}\right)$.

\section{Discussion}

B. subtilis supplementation did not significantly improve the average egg production of laying hens after feeding for 4 weeks, but it can induce a healthier microbiota composition and a higher expression of gut tight junction protein. The results prove that $B$. subtilis YW1 could serve as a potential probiotic replacement of antibiotics, and that further research on long-term B. subtilis YW1 administration is needed to confirm the effects.

Probiotics are deemed an ideal antibiotic alternative for poultry, livestock, and other farm animals, and a group of probiotic strains has been tested for their modulatory effects on animals' growth, performance, gut physical barrier functions, immune response, intestinal ABR gene profiles, microbiota composition, etc. [13,24-27]. L. plantarum B1 administration can improve the performance of broilers, modulate their gut microbiota composition, and elevate their short-chain fatty acid (SCFA) levels [14]. B. licheniformis can alleviate heat stress-induced impairments of egg production [28]. Probiotic B. subtilis can increase laying performance via several mechanisms [29-31]. Besides Bacillus and Lactobacillus, many other bacteria are used in the poultry industry as probiotics, such as Clostridium butyricum, which can counteract the diverse stresses in the body and has the ability to improve laying hens' performance and egg quality [32,33]. The present study showed that B. subtilis supplementation in the diets of laying hens can non-statistically significantly elevate overall egg production, especially in those supplemented with a low dose $\left(5 \times 10^{8} \mathrm{CFU} / \mathrm{kg}\right)$ of $B$. subtilis, without affecting the average egg weight. This could be because higher dosages of probiotics may consume more of the nutrients that birds use for egg production, but no data are available on this, so the underlying mechanisms require further exploration. Our results agree with those of many other studies, which also showed that the administration of B. subtilis DSM29784 for over 30 weeks does not significantly increase egg production. Similar results were also observed in B. subtilis CGMCC1.921- and B. subtilis PB6-treated hens [30,34,35]. Enterococcus faecalis UGRA10 can be supplemented into the diet to enhance egg production during the second half of the experimental period (40-76 days), but not during first half [16]. Our current study only lasted for 4 weeks, and so considering the duration of the production period of laying hens, further experiments employing long-term administration of B. subtilis are necessary.

Consistent with a previous study [36], Bacteriodetes, Firmicutes, Proteobacteria, Actinobacteria, and Fusobacteria are the dominant phyla in the cecum of laying hens. Normally, 
a higher bacterial richness index means a stable ecology to cope with the complex environment. In our study, no significant increase in the bacterial richness index (Alpha diversity) was shown in the group treated with B. subtilis. This reveals that B. subtilis supplementation confers little effect on the microbial population of the cecum of laying hens under the current experimental setup. Interestingly, a clear distinction between normal feed treated-and probiotic-treated groups (Beta diversity) was observed, demonstrating that B. subtilis can influence the microbial community in the cecum of laying hens. We observed an increased trend in the phyla Firmicutes in groups treated with B. subtilis, although no significant alteration was observed. Certain bacteria from Firmicutes may improve fermentation and further intestinal absorption through several mechanisms, and also affect short-chain fatty acid metabolism [37-39]. Currently, there is no general consensus on the effects of B. subtilis on the gut microbiota of laying hens at the phylum level. Cohering with our results, several studies have concluded that $B$. subtilis supplementation does not change the relative abundances of Bacteroidetes and Firmicutes in the ileal mucosa of laying hens [40,41]. Contrary to this, some researchers have demonstrated that $B$. subtilis intervention can effectively regulate the cecal microbiota's composition $[42,43]$. For instance, Li et al. showed that, compared to a control group of broilers, $B$. subtilis CGMCC can increase the relative abundances of Bacteroidetes and Proteobacteria, and accordingly reduce the ratio of Firmicutes [42]. Several factors may contribute to the different conclusions drawn from these clinical trials described above, e.g., probiotic strain specificity, host background, probiotic administration period, or dose.

A further analysis of microbiota composition at the genus level showed that B. subtilis intervention can induce a health-promoting pattern in a series of genera of cecal microbiota. An increasing trend of Lactobacillus and a significant elevation of Bifidobacterium were observed in the B. subtilis-treated group, and these beneficial bacteria are believed to effectively modulate the gut microbiota and promote gut health [44-46]. An increase in beneficial bacteria in the gut could be attributed to the indirect action of B. subtilis, since $B$. subtilis can extensively consume oxygen in the gut and promote the growth of Lactobacillus and Bifidobacterium [47,48]. Similar results were reported in other studies. Liu et al. and Forte et al. found that B. subtilis supplementation can also increase the relative ratio of Lactobacillus in chicken's guts [49,50]. Moreover, a considerable level of Campylobacter is present in chicken guts [51], and Lactobacillus can inhibit the colonization of Campylobacter in chicken's digestive tracts [52]. We observed a lower level of Campylobacter in the B. subtilis-treated groups, although it is not clear whether there is a causative relationship between Lactobacillus and Campylobacter. In addition, we observed no significant increases in the relative abundance of B. subtilis in the B. subtilis-treated group. Generally, Bacillus spp. can only establish a transient colonization of the gastrointestinal tracts of hosts, differing from Lactobacillus [53-55]. We observed a significant reduction in the relative ratio of Staphylococci in the B. subtilis-treated groups, and similar results were observed in other trials [56]. Staphylococci infection can not only cause disease in chickens, but it also poses a threat to public health due to the presence of multiple antibiotic-resistant Staphylococcus strains $[57,58]$.

Due to the extremely complex environment of the host's gut, the mechanism by which Bacillus spp. inhibit pathogens in vivo remain obscure. Piewngam et al. demonstrated that the lipopeptide and fengycin derived from probiotic Bacillus can contribute to intestinal S. aureus decolonization by inhibiting the pathogen's signaling pathway $[59,60]$. A significant reduction in the relative abundance of Fusobacteria was also observed in the $B$. subtilis-treated groups. Kollarcikova et al. discovered that the overgrowth of certain opportunistic bacteria, such as Fusobacteria, may be associated with the reduced performance of chickens, although a clear causal relationship has still yet to be established [61]. Currently, the exact effect of Fusobacteria on chicken health is still unclear, although we know it resides in the gut. Therefore, its contribution to gut homeostasis should be explored. In humans, some Fusobacterium spp. are implicated in a wide range of clinical diseases [62,63], and there is a risk of this pathogenic bacteria spreading from chickens to farmworkers. 
The intestinal epithelial cells serve as a vital physical barrier against the external environment and stimuli, such as pathogens, toxin, etc. The integrity of the epithelium is maintained by a series of intercellular junctional complexes, consisting of tight junctions, adherens junctions, and desmosomes $[64,65]$. Occludin is an important tight junction protein, and it contributes to tight junction stabilization and optimal barrier functionality. B. subtilis significantly elevates occludin's mRNA expression level in laying hens, suggesting it improves gut barrier function and optimizes the intestinal defense status. Similar results were also reported by other groups $[29,66]$, showing the effects of $B$. subtilis on the intestinal tight junction protein. Several mechanisms may be implicated in B. subtilis regulation of epithelial cells' expression of occludin. It is well known that probiotics can have inhibitory effects on gut pathogenic bacteria via adhesion with host cells [25]. Additionally, much evidence suggests that $B$. subtilis improves the expression of tight junction proteins by different mechanisms, including the mitigation of inflammatory cytokines expression (TNF- $\alpha$, IL-6) by cyclic peptide secretion $[67,68]$. Lactobacillus reuteri can induce the expression of zonula occluden-1 and occludin through the myosin light-chain kinase pathway [69], but it is still not clear whether this pathway mediates B. subtilis' regulatory effects on occludin. B. subtilis supplementation enhances epithelial barrier integrity not only in laying hens but also in broiler chickens, characterized by the increased expression of occludin at the mRNA or protein level in the gut $[66,70]$.

TLRs, crucial pattern-recognition receptors in mammals and birds, play an important role in the innate immune response via engaging with the pathogen-associated molecular patterns of microorganisms, generally leading to the activation of genes related to antior pro-inflammatory cytokines and subsequent immune activities [71,72]. No statistically significant changes in the mRNA expression levels of TLR1, TLR2, TLR4, or TLR15 were observed in our current study, indicating that B. subtilis does not trigger TLR-mediated inflammatory activity. Alternatively, B. subtilis may be capable of reducing inflammation in the chicken gut. A further trial with bacterial challenge (such as Salmonella or Campylobacter) may elucidate the anti-inflammatory effects of $B$. subtilis. In agreement with our study, several groups demonstrated that dietary supplementation with probiotics (Lactobacillus acidophilus, $B$. coagulans) in chickens does not significantly affect the expression levels of TLRs in the gut [22,73]. In contrast, several groups have demonstrated that B. subtilis treatment induces an increase or reduction in the expression levels of these TLRs in broiler chickens or chicken dendritic cells [21,74-76]. The contradictory data described above may be attributed to several factors, such as experimental period, probiotic dose, probiotic composition, strain specificity, etc. Further exploration and refined studies are needed to clarify this issue.

In conclusion, the oral administration of higher amounts of probiotic $B$. subtilis $\left(2.5 \times 10^{9} \mathrm{CFU} / \mathrm{kg}\right)$ to laying hens for 4 weeks cannot improve overall egg production, can induce a healthy pattern in microbiota composition characterized by a higher level of beneficial bacteria, and induces a higher expression level of tight junction protein. Probiotic B. subtilis supplementation at lower levels $\left(2.5 \times 10^{9} \mathrm{CFU} / \mathrm{kg}\right)$ had fewer modulatory effects. Our study shows that the B. subtilis strain YW1 possesses health-promoting abilities, and can serve as a probiotic alternative to antibiotics in the poultry industry, as well as a reference strain for clinical application.

Author Contributions: Conceptualization, G.Z.; Data curation, X.T., A.R. and W.L.; Formal analysis, H.W.; Funding acquisition, Y.J., S.C. and T.Q.; Investigation, J.Z., M.W., L.L., Y.Q., Y.Z. and Y.J.; Methodology, G.Z., H.W., J.Z., X.T., A.R., M.W., W.L., L.L., Y.Z., Y.J., S.C. and T.Q.; Project administration, T.Q.; Resources, Y.Q., S.C. and T.Q.; Writing-original draft, G.Z. and H.W.; Writing-review \& editing, G.Z. and T.Q. All authors have read and agreed to the published version of the manuscript.

Funding: This work was supported by the Agricultural Science and Technology Innovation Program (Grant number: ASTIP-IAS15), Beijing Innovation Consortium of Agriculture Research System (BAIC04-2021) and Central Public-interest Scientific Institution Basal Research Fund (Grant number: 2021-YWF-ZYSQ-10). 
Institutional Review Board Statement: The study was conducted according to the guidelines of the Declaration of Helsinki, and approved by the Ethics Committee of Institute of Animal Sciences, Chinese Academy of Agricultural Sciences (IAS2019-71, approved on 10 February 2019).

Informed Consent Statement: Not applicable.

Data Availability Statement: All data are available from the corresponding authors on reasonable request.

Conflicts of Interest: The authors declare that the research was conducted in the absence of any commercial or financial relationships that could be construed as a potential conflict of interest.

\section{References}

1. Gaskins, H.R.; Collier, C.T.; Anderson, D.B. Antibiotics as growth promotants: Mode of action. Anim. Biotechnol. 2002, 13, 29-42. [CrossRef] [PubMed]

2. Diarra, M.S.; Malouin, F. Antibiotics in Canadian poultry productions and anticipated alternatives. Front. Microbiol. 2014, 5, 282. [CrossRef] [PubMed]

3. Kim, J.; Hwang, B.K.; Choi, H.; Wang, Y.; Choi, S.H.; Ryu, S.; Jeon, B. Characterization of mcr-1-Harboring Plasmids from Pan Drug-Resistant Escherichia coli Strains Isolated from Retail Raw Chicken in South Korea. Microorganisms 2019, 7, 344. [CrossRef] [PubMed]

4. Lambrecht, E.; Van Coillie, E.; Van Meervenne, E.; Boon, N.; Heyndrickx, M.; Van de Wiele, T. Commensal, E. coli rapidly transfer antibiotic resistance genes to human intestinal microbiota in the Mucosal Simulator of the Human Intestinal Microbial Ecosystem (M-SHIME). Int. J. Food Microbiol. 2019, 311, 108357. [CrossRef] [PubMed]

5. Vinueza-Burgos, C.; Ortega-Paredes, D.; Narváez, C.; De Zutter, L.; Zurita, J. Characterization of cefotaxime resistant Escherichia coli isolated from broiler farms in Ecuador. PLoS ONE 2019, 14, e0207567. [CrossRef] [PubMed]

6. Al-Khalaifah, H.S. Benefits of probiotics and/or prebiotics for antibiotic-reduced poultry. Poult. Sci. 2018, 97, 3807-3815. [CrossRef] [PubMed]

7. Danzeisen, J.L.; Calvert, A.J.; Noll, S.L.; McComb, B.; Sherwood, J.S.; Logue, C.M.; Johnson, T.J. Succession of the turkey gastrointestinal bacterial microbiome related to weight gain. Peerj 2013, 1, e237. [CrossRef] [PubMed]

8. WHO. Report of a Joint FAO/WHO Working Group on Drafting Guidelines for the Evaluation of Probiotics in Food. 2002 Available online: https://www.who.int/foodsafety/fs_management/en/probiotic_guidelines.pdf (accessed on 1 May 2002).

9. Seal, B.S.; Drider, D.; Oakley, B.B.; Brüssow, H.; Bikard, D.; Rich, J.O.; Miller, S.; Devillard, E.; Kwan, J.; Bertin, G.; et al. Microbial-derived products as potential new antimicrobials. Vet. Res. 2018, 49, 66. [CrossRef] [PubMed]

10. Saint-Cyr, M.J.; Guyard-Nicodème, M.; Messaoudi, S.; Chemaly, M.; Cappelier, J.M.; Dousset, X.; Haddad, N. Recent Advances in Screening of Anti-Campylobacter Activity in Probiotics for Use in Poultry. Front. Microbiol. 2016, 7, 553. [CrossRef] [PubMed]

11. Al-Khalaifa, H.; Al-Nasser, A.; Al-Surayee, T.; Al-Kandari, S.; Al-Enzi, N.; Al-Sharrah, T.; Ragheb, G.; Al-Qalaf, S.; Mohammed, A. Effect of dietary probiotics and prebiotics on the performance of broiler chickens. Poult. Sci. 2019, 98, 4465-4479. [CrossRef] [PubMed]

12. Ward, T.L.; Weber, B.P.; Mendoza, K.M.; Danzeisen, J.L.; Llop, K.; Lang, K.; Clayton, J.B.; Grace, E.; Brannon, J.; Radovic, I.; et al. Antibiotics and Host-Tailored Probiotics Similarly Modulate Effects on the Developing Avian Microbiome, Mycobiome, and Host Gene Expression. Mbio 2019, 10. [CrossRef] [PubMed]

13. Shokryazdan, P.; Faseleh Jahromi, M.; Liang, J.B.; Ramasamy, K.; Sieo, C.C.; Ho, Y.W. Effects of a Lactobacillus salivarius mixture on performance, intestinal health and serum lipids of broiler chickens. PLoS ONE 2017, 12, e0175959. [CrossRef]

14. Peng, Q.; Zeng, X.F.; Zhu, J.L.; Wang, S.; Liu, X.T.; Hou, C.L.; Thacker, P.A.; Qiao, S.Y. Effects of dietary Lactobacillus plantarum B1 on growth performance, intestinal microbiota, and short chain fatty acid profiles in broiler chickens. Poult. Sci. 2016, 95, 893-900. [CrossRef] [PubMed]

15. Bai, K.; Feng, C.; Jiang, L.; Zhang, L.; Zhang, J.; Zhang, L.; Wang, T. Dietary effects of Bacillus subtilis fmbj on growth performance, small intestinal morphology, and its antioxidant capacity of broilers. Poult. Sci. 2018, 97, 2312-2321. [CrossRef]

16. Peralta-Sánchez, J.M.; Martín-Platero, A.M.; Ariza-Romero, J.J.; Rabelo-Ruiz, M.; Zurita-González, M.J.; Baños, A.; RodríguezRuano, S.M.; Maqueda, M.; Valdivia, E.; Martínez-Bueno, M. Egg Production in Poultry Farming Is Improved by Probiotic Bacteria. Front. Microbiol. 2019, 10, 1042. [CrossRef] [PubMed]

17. Zhang, G.; Ducatelle, R.; De Bruyne, E.; Joosten, M.; Bosschem, I.; Smet, A.; Haesebrouck, F.; Flahou, B. Role of gammaglutamyltranspeptidase in the pathogenesis of Helicobacter suis and Helicobacter pylori infections. Vet. Res. 2015, 46, 31. [CrossRef] [PubMed]

18. Livak, K.J.; Schmittgen, T.D. Analysis of relative gene expression data using real-time quantitative PCR and the 2(-Delta Delta C(T)) Method. Methods 2001, 25, 402-408. [CrossRef]

19. Shao, Y.; Guo, Y.; Wang, Z. beta-1,3/1,6-Glucan alleviated intestinal mucosal barrier impairment of broiler chickens challenged with Salmonella enterica serovar Typhimurium. Poult. Sci. 2013, 92, 1764-1773. [CrossRef]

20. Borowska, D.; Rothwell, L.; Bailey, R.A.; Watson, K.; Kaiser, P. Identification of stable reference genes for quantitative PCR in cells derived from chicken lymphoid organs. Vet. Immunol. Immunopathol. 2016, 170, 20-24. [CrossRef] 
21. Rajput, I.R.; Ying, H.; Yajing, S.; Arain, M.A.; Weifen, L.; Ping, L.; Bloch, D.M.; Wenhua, L. Saccharomyces boulardii and Bacillus subtilis B10 modulate TLRs and cytokines expression patterns in jejunum and ileum of broilers. PLoS ONE 2017, 12, e0173917.

22. Zhen, W.; Shao, Y.; Gong, X.; Wu, Y.; Geng, Y.; Wang, Z.; Guo, Y. Effect of dietary Bacillus coagulans supplementation on growth performance and immune responses of broiler chickens challenged by Salmonella enteritidis. Poult. Sci. 2018, 97, 2654-2666. [CrossRef]

23. Zhang, R.; Yu, Q.; Shi, G.; Liu, R.; Zhang, W.; Zhao, X.; Li, G.; Ge, M. chTLR4 pathway activation by Astragalus polysaccharide in bursa of Fabricius. BMC Vet. Res. 2017, 13, 119. [CrossRef]

24. Gao, P.F.; Hou, Q.C.; Kwok, L.Y.; Huo, D.X.; Feng, S.Z.; Zhang, H.P. Effect of feeding Lactobacillus plantarum P-8 on the faecal microbiota of broiler chickens exposed to lincomycin. Sci. Bull. 2017, 62, 105-113. [CrossRef]

25. Wang, J.; Zeng, Y.; Wang, S.; Liu, H.; Zhang, D.; Zhang, W.; Wang, Y.; Ji, H. Swine-Derived Probiotic Lactobacillus plantarum Inhibits Growth and Adhesion of Enterotoxigenic Escherichia coli and Mediates Host Defense. Front. Microbiol. 2018, 9, 1364. [CrossRef] [PubMed]

26. Xu, H.Y.; Huang, W.Q.; Hou, Q.C.; Kwok, L.Y.; Sun, Z.H.; Ma, H.M.; Zhao, F.Y.; Lee, Y.K.; Zhang, H.P. The effects of probiotics administration on the milk production, milk components and fecal bacteria microbiota of dairy cows. Sci. Bull. 2017, 62, 767-774. [CrossRef]

27. Jaramillo-Torres, A.; Rawling, M.D.; Rodiles, A.; Mikalsen, H.E.; Johansen, L.H.; Tinsley, J.; Forberg, T.; Aasum, E.; Castex, M.; Merrifield, D.L. Influence of Dietary Supplementation of Probiotic Pediococcus acidilactici MA18/5M during the Transition from Freshwater to Seawater on Intestinal Health and Microbiota of Atlantic Salmon (Salmo salar L.). Front. Microbiol. 2019, 10, 2243. [CrossRef]

28. Deng, W.; Dong, X.F.; Tong, J.M.; Zhang, Q. The probiotic Bacillus licheniformis ameliorates heat stress-induced impairment of egg production, gut morphology, and intestinal mucosal immunity in laying hens. Poult. Sci. 2012, 91, 575-582. [CrossRef] [PubMed]

29. Chen, J.F.; Xu, M.M.; Kang, K.L.; Tang, S.G.; He, C.Q.; Qu, X.Y.; Guo, S.C. The effects and combinational effects of Bacillus subtilis and montmorillonite on the intestinal health status in laying hens. Poult. Sci. 2020, 99, 1311-1319. [CrossRef]

30. Guo, J.R.; Dong, X.F.; Liu, S.; Tong, J.M. Effects of long-term Bacillus subtilis CGMCC 1.921 supplementation on performance, egg quality, and fecal and cecal microbiota of laying hens. Poult. Sci. 2017, 96, 1280-1289. [CrossRef]

31. Prazdnova, E.V.; Mazanko, M.S.; Chistyakov, V.A.; Denisenko, Y.V.; Makarenko, M.S.; Usatov, A.V.; Bren, A.B.; Tutelyan, A.V.; Komarova, Z.B.; Gorlov, I.F.; et al. Effect of Bacillus subtilis KATMIRA1933 and Bacillus amyloliquefaciens B-1895 on the productivity, reproductive aging, and physiological characteristics of hens and roosters. Benef. Microbes 2019, 10, 395-412. [CrossRef]

32. Xiang, Q.; Wang, C.; Zhang, H.; Lai, W.; Wei, H.; Peng, J. Effects of Different Probiotics on Laying Performance, Egg Quality, Oxidative Status, and Gut Health in Laying Hens. Animals 2019, 9, 1110. [CrossRef]

33. Zhan, H.Q.; Dong, X.Y.; Li, L.L.; Zheng, Y.X.; Gong, Y.J.; Zou, X.T. Effects of dietary supplementation with Clostridium butyricum on laying performance, egg quality, serum parameters, and cecal microflora of laying hens in the late phase of production. Poult. Sci. 2019, 98, 896-903. [CrossRef]

34. Neijat, M.; Shirley, R.B.; Barton, J.; Thiery, P.; Welsher, A.; Kiarie, E. Effect of dietary supplementation of Bacillus subtilis DSM29784 on hen performance, egg quality indices, and apparent retention of dietary components in laying hens from 19 to 48 weeks of age. Poult. Sci. 2019, 98, 5622-5635. [CrossRef]

35. Forte, C.; Moscati, L.; Acuti, G.; Mugnai, C.; Franciosini, M.P.; Costarelli, S.; Cobellis, G.; Trabalza-Marinucci, M. Effects of dietary Lactobacillus acidophilus and Bacillus subtilis on laying performance, egg quality, blood biochemistry and immune response of organic laying hens. J. Anim. Physiol. Anim. Nutr. 2016, 100, 977-987. [CrossRef] [PubMed]

36. Schreuder, J.; Velkers, F.C.; Bouwstra, R.J.; Beerens, N.; Stegeman, J.A.; de Boer, W.F.; Elbers, A.R.W.; van Hooft, P.; Feberwee, A.; Bossers, A.; et al. Limited changes in the fecal microbiome composition of laying hens after oral inoculation with wild duck feces. Poult. Sci. 2019, 98, 6542-6551. [CrossRef] [PubMed]

37. Delzenne, N.M.; Cani, P.D. Interaction between obesity and the gut microbiota: Relevance in nutrition. Annu. Rev. Nutr. 2011, 31, 15-31. [CrossRef] [PubMed]

38. Oakley, B.B.; Lillehoj, H.S.; Kogut, M.H.; Kim, W.K.; Maurer, J.J.; Pedroso, A.; Lee, M.D.; Collett, S.R.; Johnson, T.J.; Cox, N.A. The chicken gastrointestinal microbiome. FEMS Microbiol. Lett. 2015, 360, 100-112. [CrossRef]

39. Elokil, A.A.; Magdy, M.; Melak, S.; Ishfaq, H.; Bhuiyan, A.; Cui, L.; Jamil, M.; Zhao, S.; Li, S. Faecal microbiome sequences in relation to the egg-laying performance of hens using amplicon-based metagenomic association analysis. Animal 2020, 14, 706-715.

40. Guo, J.R.; Dong, X.F.; Liu, S.; Tong, J.M. High-throughput sequencing reveals the effect of Bacillus subtilis CGMCC 1.921 on the cecal microbiota and gene expression in ileum mucosa of laying hens. Poult. Sci. 2018, 97, 2543-2556. [CrossRef] [PubMed]

41. Neijat, M.; Habtewold, J.; Shirley, R.B.; Welsher, A.; Barton, J.; Thiery, P.; Kiarie, E. Bacillus subtilis Strain DSM 29784 Modulates the Cecal Microbiome, Concentration of Short-Chain Fatty Acids, and Apparent Retention of Dietary Components in Shaver White Chickens during Grower, Developer, and Laying Phases. Appl. Environ. Microbiol. 2019, 85. [CrossRef] [PubMed]

42. Li, Y.; Xu, Q.; Huang, Z.; Lv, L.; Liu, X.; Yin, C.; Yan, H.; Yuan, J. Effect of Bacillus subtilis CGMCC 1.1086 on the growth performance and intestinal microbiota of broilers. J. Appl. Microbiol. 2016, 120, 195-204. [CrossRef] [PubMed]

43. Li, X.; Wu, S.; Li, X.; Yan, T.; Duan, Y.; Yang, X.; Duan, Y.; Sun, Q.; Yang, X. Simultaneous Supplementation of Bacillus subtilis and Antibiotic Growth Promoters by Stages Improved Intestinal Function of Pullets by Altering Gut Microbiota. Front. Microbiol. 2018, 9, 2328. [CrossRef] [PubMed] 
44. Miyamoto, T.; Horie, T.; Fujiwara, T.; Fukata, T.; Sasai, K.; Baba, E. Lactobacillus flora in the cloaca and vagina of hens and its inhibitory activity against Salmonella enteritidis in vitro. Poult. Sci. 2000, 79, 7-11. [CrossRef] [PubMed]

45. Khan, S.; Moore, R.J.; Stanley, D.; Chousalkar, K.K. Gut microbiota of laying hens and its manipulation with prebiotics and probiotics to enhance gut health and food safety. Appl. Environ. Microbiol. 2020. [CrossRef]

46. Markazi, A.; Luoma, A.; Shanmugasundaram, R.; Mohnl, M.; Raj Murugesan, G.; Selvaraj, R. Effects of drinking water synbiotic supplementation in laying hens challenged with Salmonella. Poult. Sci. 2018, 97, 3510-3518. [CrossRef] [PubMed]

47. Gao, Z.; Wu, H.; Shi, L.; Zhang, X.; Sheng, R.; Yin, F.; Gooneratne, R. Study of Bacillus subtilis on growth performance, nutrition metabolism and intestinal microflora of 1 to $42 \mathrm{~d}$ broiler chickens. Anim. Nutr. 2017, 3, 109-113. [CrossRef] [PubMed]

48. Yu, T.; Kong, J.; Zhang, L.; Gu, X.; Wang, M.; Guo, T. New crosstalk between probiotics Lactobacillus plantarum and Bacillus subtilis. Sci. Rep. 2019, 9, 1-9. [CrossRef]

49. Liu, Y.L.; Yan, T.; Li, X.Y.; Duan, Y.L.; Yang, X.; Yang, X.J. Effects of Bacillus subtilis and antibiotic growth promoters on the growth performance, intestinal function and gut microbiota of pullets from 0 to 6 weeks. Animal 2020, 14, 1619-1628. [CrossRef]

50. Forte, C.; Acuti, G.; Manuali, E.; Casagrande Proietti, P.; Pavone, S.; Trabalza-Marinucci, M.; Moscati, L.; Onofri, A.; Lorenzetti, C.; Franciosini, M.P. Effects of two different probiotics on microflora, morphology, and morphometry of gut in organic laying hens. Poult. Sci. 2016, 95, 2528-2535. [CrossRef] [PubMed]

51. Kaakoush, N.O.; Sodhi, N.; Chenu, J.W.; Cox, J.M.; Riordan, S.M.; Mitchell, H.M. The Interplay between Helicobacter and Campylobacter Species and Other Gastrointestinal Microbiota of Commercial Broiler Chickens. Helicobacter 2014, 19, 158. [CrossRef]

52. Kobierecka, P.A.; Wyszyńska, A.K.; Aleksandrzak-Piekarczyk, T.; Kuczkowski, M.; Tuzimek, A.; Piotrowska, W.; Górecki, A.; Adamska, I.; Wieliczko, A.; Bardowski, J.; et al. In vitro characteristics of Lactobacillus spp. strains isolated from the chicken digestive tract and their role in the inhibition of Campylobacter colonization. Microbiologyopen 2017, 6, e00512. [CrossRef] [PubMed]

53. Cartman, S.T.; La Ragione, R.M.; Woodward, M.J. Bacillus subtilis spores germinate in the chicken gastrointestinal tract. Appl. Environ. Microbiol. 2008, 74, 5254-5258. [CrossRef]

54. Ghelardi, E.; Celandroni, F.; Salvetti, S.; Gueye, S.A.; Lupetti, A.; Senesi, S. Survival and persistence of Bacillus clausii in the human gastrointestinal tract following oral administration as spore-based probiotic formulation. J. Appl. Microbiol. 2015, 119, 552-559. [CrossRef] [PubMed]

55. Stephenson, D.P.; Moore, R.J.; Allison, G.E. Lactobacillus Strain Ecology and Persistence within Broiler Chickens Fed Different Diets: Identification of Persistent Strains. Appl. Environ. Microbiol. 2010, 76, 6494-6503. [CrossRef] [PubMed]

56. De Cesare, A.; Caselli, E.; Lucchi, A.; Sala, C.; Parisi, A.; Manfreda, G.; Mazzacane, S. Impact of a probiotic-based cleaning product on the microbiological profile of broiler litters and chicken caeca microbiota. Poult. Sci. 2019, 98, 3602-3610. [CrossRef]

57. Fijalkowski, K.; Peitler, D.; Karakulska, J. Staphylococci isolated from ready-to-eat meat-Identification, antibiotic resistance and toxin gene profile. Int. J. Food Microbiol. 2016, 238, 113-120. [CrossRef] [PubMed]

58. Huber, H.; Ziegler, D.; Pflüger, V.; Vogel, G.; Zweifel, C.; Stephan, R. Prevalence and characteristics of methicillin-resistant coagulase-negative staphylococci from livestock, chicken carcasses, bulk tank milk, minced meat, and contact persons. BMC Vet. Res. 2011, 7, 6. [CrossRef] [PubMed]

59. Piewngam, P.; Zheng, Y.; Nguyen, T.H.; Dickey, S.W.; Joo, H.S.; Villaruz, A.E.; Glose, K.A.; Fisher, E.L.; Hunt, R.L.; Li, B.; et al. Pathogen elimination by probiotic Bacillus via signalling interference. Nature 2018, 562, 532-537. [CrossRef] [PubMed]

60. York, A. Silencing Staphylococcus aureus with probiotics. Nat. Rev. Microbiol. 2018, 16, 715. [CrossRef] [PubMed]

61. Kollarcikova, M.; Kubasova, T.; Karasova, D.; Crhanova, M.; Cejkova, D.; Sisak, F.; Rychlik, I. Use of 16S rRNA gene sequencing for prediction of new opportunistic pathogens in chicken ileal and cecal microbiota. Poult. Sci. 2019, 98, 2347-2353. [CrossRef]

62. Han, Y.W. Fusobacterium nucleatum: A commensal-turned pathogen. Curr. Opin. Microbiol. 2015, 23, 141-147. [CrossRef]

63. Afra, K.; Laupland, K.; Leal, J.; Lloyd, T.; Gregson, D. Incidence, risk factors, and outcomes of Fusobacterium species bacteremia. BMC Infect. Dis. 2013, 13, 264. [CrossRef]

64. Schneeberger, E.E.; Lynch, R.D. The tight junction: A multifunctional complex. Am. J. Physiol. Cell Physiol. 2004, 286, C1213-C1228 [CrossRef] [PubMed]

65. Awad, W.A.; Hess, C.; Hess, M. Enteric Pathogens and Their Toxin-Induced Disruption of the Intestinal Barrier through Alteration of Tight Junctions in Chickens. Toxins 2017, 9, 60. [CrossRef] [PubMed]

66. Park, I.; Lee, Y.; Goo, D.; Zimmerman, N.P.; Smith, A.H.; Rehberger, T.; Lillehoj, H.S. The effects of dietary Bacillus subtilis supplementation, as an alternative to antibiotics, on growth performance, intestinal immunity, and epithelial barrier integrity in broiler chickens infected with Eimeria maxima. Poult. Sci. 2020, 99, 725-733. [CrossRef]

67. Gong, Y.; Li, H.; Li, Y. Effects of Bacillus subtilis on epithelial tight junctions of mice with inflammatory bowel disease. J. Interferon Cytokine Res. 2016, 36, 75-85. [CrossRef]

68. Selvam, R.; Maheswari, P.; Kavitha, P.; Ravichandran, M.; Sas, B.; Ramchand, C.N. Effect of Bacillus subtilis PB6, a natural probiotic on colon mucosal inflammation and plasma cytokines levels in inflammatory bowel disease. Indian J. Biochem. Biophys. 2009, 46, 79-85. [PubMed]

69. Yi, H.; Wang, L.; Xiong, Y.; Wang, Z.; Qiu, Y.; Wen, X.; Jiang, Z.; Yang, X.; Ma, X. Lactobacillus reuteri LR1 Improved Expression of Genes of Tight Junction Proteins via the MLCK Pathway in IPEC-1 Cells during Infection with Enterotoxigenic Escherichia coli K88. Mediat. Inflamm. 2018, 2018, 6434910. [CrossRef] 
70. Song, J.; Xiao, K.; Ke, Y.L.; Jiao, L.F.; Hu, C.H.; Diao, Q.Y.; Shi, B.; Zou, X.T. Effect of a probiotic mixture on intestinal microflora, morphology, and barrier integrity of broilers subjected to heat stress. Poult. Sci. 2014, 93, 581-588. [CrossRef] [PubMed]

71. Kawasaki, T.; Kawai, T. Toll-like receptor signaling pathways. Front. Immunol. 2014, 5, 461. [CrossRef]

72. Chen, S.; Cheng, A.; Wang, M. Innate sensing of viruses by pattern recognition receptors in birds. Vet. Res. 2013, 44, 82. [CrossRef] [PubMed]

73. Asgari, F.; Falak, R.; Teimourian, S.; Pourakbari, B.; Ebrahimnezhad, S.; Shekarabi, M. Effects of Oral Probiotic Feeding on Toll-Like Receptor Gene Expression of the Chicken's Cecal Tonsil. Rep. Biochem. Mol. Biol. 2018, 6, 151-157. [PubMed]

74. Rajput, I.R.; Hussain, A.; Li, Y.L.; Zhang, X.; Xu, X.; Long, M.Y.; You, D.Y.; Li, W.F. Saccharomyces boulardii and Bacillus subtilis B10 modulate TLRs mediated signaling to induce immunity by chicken BMDCs. J. Cell Biochem. 2014, 115, 189-198. [CrossRef]

75. Dong, Y.; Li, R.; Liu, Y.; Ma, L.; Zha, J.; Qiao, X.; Chai, T.; Wu, B. Benefit of Dietary Supplementation with Bacillus subtilis BYS2 on Growth Performance, Immune Response, and Disease Resistance of Broilers. Probiotics Antimicrob. Proteins 2020, 12, 1385-1397. [CrossRef] [PubMed]

76. Yitbarek, A.; Echeverry, H.; Munyaka, P.; Rodriguez-Lecompte, J.C. Innate immune response of pullets fed diets supplemented with prebiotics and synbiotics. Poult. Sci. 2015, 94, 1802-1811. [CrossRef] [PubMed] 